\title{
Clinical outcome of stream light Trans-PRK for correction of moderate to high Myopic Astigmatism
}

\author{
Sherif H Emerah, MD FRCS
}

\author{
Associate Professor of ophthalmology, \\ Research Institute of ophthalmology, Giza, \\ Egypt. \\ Correspondence to Sherif H. Emerah, MD, . \\ Tel: +201222459388 \\ mails: sherifemera@yahoo.com \\ The Egyptian Journal of Cataract and \\ Refractive Surgery 2020
}

\begin{abstract}
Aim: To evaluate the results of stream light trans photorefractive keratectomy (t- PRK) procedure in the treatment of moderate to high myopic astigmatism.

Methods: In this retrospective case series, 30 eyes of 15 patients with age between 18 and 34 years who underwent trans PRK treatment for high astigmatism were enrolled. trans PRK was performed using Alcon WaveLight EX500. Visual and refractive outcomes were assessed at 1, 3 and 6 months after the treatment.
\end{abstract}

\begin{abstract}
Results: The mean preoperative manifest astigmatism was $3.2 \pm 0.9 \mathrm{D}$. The mean preoperative spherical equivalent $-2.8 \pm 1.45 \mathrm{D}$. The mean preoperative BCDVA $0.9 \pm 0.08$ Decimal. At 6 months post-surgery, the mean postoperative UCDVA $1.06 \pm 0.13$ Decimal. The mean postoperative spherical equivalent $0.16 \pm 0.27 \mathrm{D}$. The mean postoperative residual refractive cylinder was $0.4 \pm 0.26 \mathrm{D}$. Eyes with postoperative residual refractive cylinder of $0.5 \mathrm{D}$ or less represented $70 \%$ (21 eyes). Eyes with postoperative residual refractive cylinder of $0.75 \mathrm{D}$ or less represented $100 \%$ (30 eyes). Two eyes $(6.6 \%)$ have non-significant paracentral corneal haze grade 1 during the follow up time.
\end{abstract}

Conclusion: The study showed that trans (stream light) PRK with MMC is effective, safe and predictable method in the treatment of moderate to high myopic astigmatism.

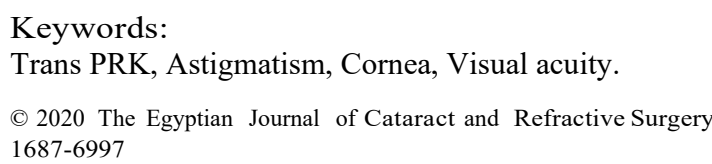

\section{Introduction}

Photorefractive keratectomy (PRK) has been commonly used as an effective and safe technique for corneal refractive surgeries. ${ }^{1-3}$ In PRK, the corneal epithelium should be removed first before stromal ablation. ${ }^{4}$ There are several techniques for epithelial debridement including mechanical, chemical, rotating brush, and with Excimer laser.

Previous studies reported that all of these epithelial removal methods are effective for surgical correction of refractive errors. ${ }^{5-9}$ Mechanical debridement is the most common technique for epithelial debridement. Although mechanical technique is effective, it has some problems, especially for inexperienced surgeons. Alcohol may have toxic effects on corneal stem cells. 10 Increased epithelial debridement time increase stromal dehydration due to evaporation. 11

Surface corneal laser ablation had advantages of avoiding flap complications and offer greater stability of postoperative corneal biomechanics than LASIK. ${ }^{12}$ Compared with LASIK for correcting high error, surface ablation preserves more stromal tissue, thus avoiding the potential risk of corneal ectasia.$^{13}$

For decades, PRK has been a well-established and safe surface ablation technique to correct low to moderate myopia and astigmatism. Recently, A new procedure, trans-epithelial photorefractive keratectomy (t-PRK), was introduced as an alternative to classic PRK. This avoided the need for mechanical or chemical removal of the epithelium. ${ }^{14,15}$ T-PRK requires one-step removal of the epithelium and stroma. T-PRK takes less surgery time, less postoperative pain and discomfort, faster epithelial healing and faster visual recovery than conventional PRK. ${ }^{16}$

StreamLight ${ }^{\mathrm{TM}}$ is a novel, one-step t-PRK procedure in which the epithelium is first removed by phototherapeutic keratectomy (PTK) directly followed by PRK in a single procedure using the Wavelight EX500 excimer laser.

The purpose of this study is to evaluate visual and refractive results of t-PRK procedure in the treatment of moderate to high myopic astigmatism.

\section{Subjects and methods}

In this retrospective study, the visual and refractive outcomes of patients who underwent t- PRK to correct moderate to high myopic astigmatism were investigated. The study complied the principles outlined in the declaration of Helsinki. Written consent was obtained from all patients. Patients were considered eligible if they were over 18 years of age, had a moderate to high myopic astigmatism with stable refraction for at least 2 years. Eligible patients had no other ocular and general pathology.

\footnotetext{
This is an open access journal, and articles are distributed under the terms of the Creative Commons Attribution-NonCommercial-ShareAlike 4.0 License, which allows others to remix, tweak, and build upon the work non-commercially, as long as appropriate credit is given and the new creations are licensed under the identical terms.
} 
Patients with a history of previous refractive surgery, unstable refraction, keratoconus, form-fruste keratoconus, and an ablation that would leave less than 400 microns of residual stromal bed were excluded.

The preoperative evaluation consisted of a comprehensive eye examination including measurements of Uncorrected Distance Visual acuity (UCDVA), best corrected distance visual acuity (BCDVA), manifest and cycloplegic refraction, intraocular pressure (IOP), pupil size and a dilated fundus examination. Corneal topography was obtained with Topolyzer Vario (Alcon Surgical, Fort Worth, TX, USA) and The Pentacam (OCULUS Optikgeräte GmbH, Wetzlar, Germany).

All surgeries were performed using the WaveLight EX500 (Alcon surgical, Fort Worth, Texas, USA) using WaveLight nomogram which based on manifest refraction. StreamLight TM software enables an equal ablation of the epithelium over the treatment zone $(7 \mathrm{~mm}$ for myopia and $9 \mathrm{~mm}$ for myopic astigmatism).

Preoperatively, each eye received one drop of proparacaine. Cornea was pre-cooled with chilled BSS for 30s. After removing excessive liquid from the conjunctiva and cornea with a dry sponge, epithelial removal was performed using the Stream-Light ${ }^{\mathrm{TM}}$ PTK mode for 22-30s depending on pre-existing refractive error. Stream-Light ${ }^{\mathrm{TM}}$ mode allows to adjust the epithelial ablation depth between 45 and $65 \mu \mathrm{m}$ according to the epithelial mapping. In our daily practice we usually adjust the epithelial ablation depth on $55 \mu \mathrm{m}$. The Stream-light ${ }^{\mathrm{TM}}$ PTK mode is optimized not to induce any refractive shift. After the PTK mode, the cornea was checked and any remaining epithelial cells were removed mechanically with a dry sponge. After an interruption time of around 10s to cool down the cornea, PRK laser ablation mode was applied followed by 1 minute cooling of the cornea with chilled BSS.
After laser ablation, MMC $(0.02 \mathrm{mg} / \mathrm{cc})$ was applied with a weck cell sponge for 30-40 seconds, and thoroughly irrigated with $20 \mathrm{~mm}$ of balanced salt solution. one drop of $0.3 \%$ tobramycin dexamethasone and a topical nonsteroidal anti-inflammatory drug were instilled. A soft bandage contact lens was applied.

Postoperatively, moxifloxacin $0.5 \%$ was prescribed four times daily for 1 week. After complete reepithelialization, the bandage contact lens was removed. Fluorometholone 0.1 eye drop was started every $6 \mathrm{~h}$ and tapered over 2 months. Non preservative Artificial tears was prescribed 6 times per day for 2-3 months.

The postoperative evaluation included a slit lamp examination, UCDVA, residual refractive astigmatism evaluation and BCDVA measurements.

\section{Results}

This is a retrospective clinical study that included 30 eyes of 15 patients. Patients includes 9 females and 6 males. The mean age of the patients was $28.2 \pm 5.9$ years (range $19-34$ years). The mean preoperative manifest astigmatism was $3.2 \pm 0.9 \mathrm{D}$ (range from 2.5 to $5.25 \mathrm{D}$ ). The mean preoperative mean spherical equivalent (MSE) $-2.8 \pm 1.45 \mathrm{D}$ (range from -1.625 to -4.75 ). The mean preoperative BCDVA $0.9 \pm 0.08$ Decimal (range from 0.8 to 1.0). At 6 months post-surgery, the mean postoperative UCDVA $1.06 \pm 0.13$ Decimal (range from 0.8 to 1.2 ). The postoperative MSE $0.16 \pm 0.27 \mathrm{D}$ (range from -0.13 to +0.63$)$. The mean postoperative residual refractive cylinder was $0.4 \pm 0.26 \mathrm{D}$ (range $0.0-0.75$ D). Eyes with postoperative residual refractive cylinder of $0.5 \mathrm{D}$ or less represented $70 \%$ ( 21 eyes). Eyes with postoperative residual refractive cylinder of $0.75 \mathrm{D}$ or less represented $100 \%$ (30 eyes). Sixty percent of eyes $(18 / 30)$ gain more than 1-2 lines. Two eyes (6.6\%) have non-significant paracentral corneal haze grade 1 during the follow up time.



Fig. 1 


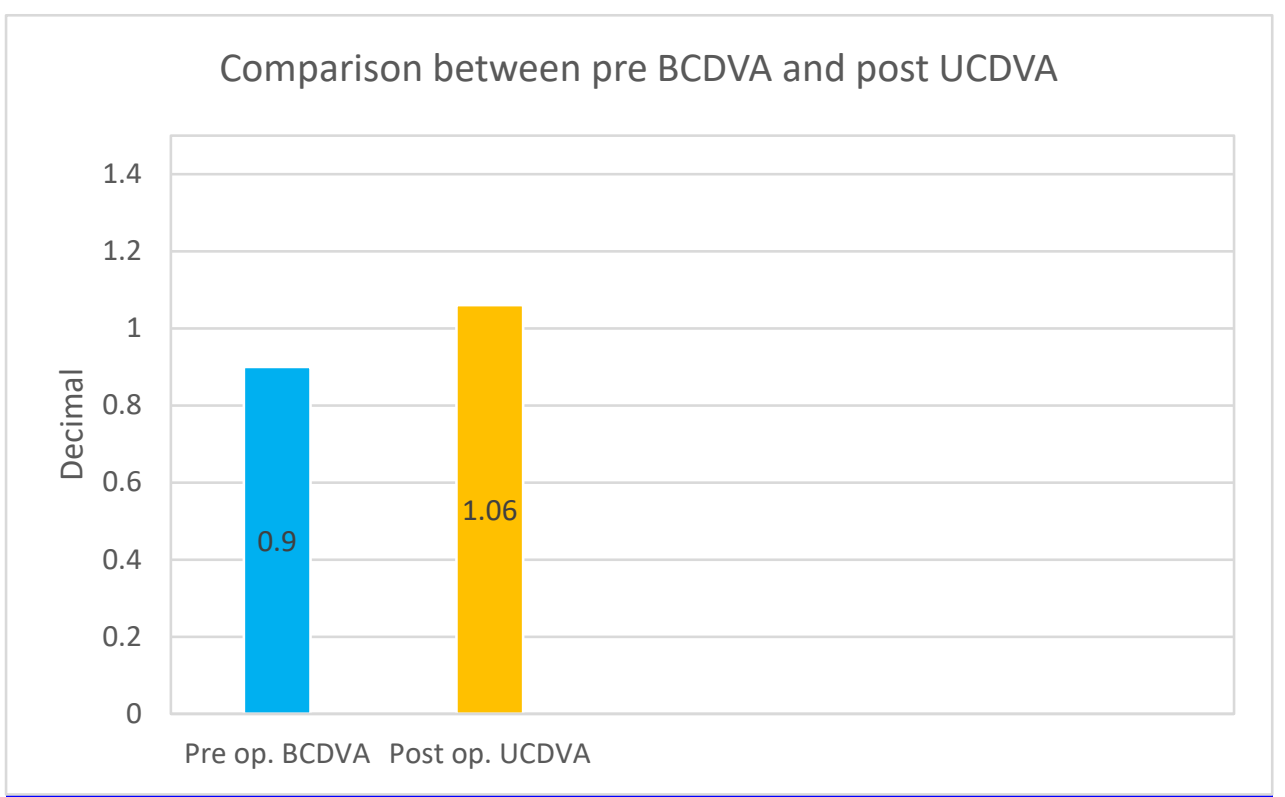

Fig. 2

\section{Discussion}

In a study compared the results of three PRK procedures in the treatment of astigmatism.

The percentage of MRSE of within $\pm 0.50 \mathrm{D}$ was $100 \%$ in PRK with MMC Group, $100 \%$ in PRK without MMC Group, and 93.9\%) in t-PRK Group. The study showed that PRK without MMC, PRK with MMC and T-PRK appears to have similar efficiency, safety and predictability in the treatment of astigmatism. The incidence of corneal haze was also similar between the three groups. ${ }^{17}$

Jun et al ${ }^{18}$ compared the clinical outcomes of wavefrontoptimized (WFO) t-PRK and corneal wavefront-guided (CWFG) t-PRK for myopic eyes with moderate to high astigmatism. They concluded that both techniques are safe and effective for correcting moderate to high astigmatism. However, CWFG t-PRK provides a more predictable astigmatism correction axis and fewer induced corneal aberrations. Most eyes achieving a nonvisually significant astigmatism at the final postoperative visit $(0.34 \pm 0.40 \mathrm{D})$ which is comparable to our results $(0.4 \pm 0.26 \mathrm{D})$.

Gadde et al ${ }^{19}$ compared the visual outcome, safety, efficacy and corneal transparency between single-step trans-epithelial photorefractive keratectomy (t-PRK) and conventional photorefractive keratectomy (PRK), they showed that Single-step t-PRK and PRK provided similar results with regards to post-operative UCDVA, postoperative BCDVA. Clinically significant corneal haze occurs in a very small percentage of eyes $(0.3 \%$ to $3 \%$ ). In both the groups, none of the eyes lost postoperative BCDVA at the end of mean follow-up period of 3.5 months. They concluded that both procedures are predictable, effective, and safe for correction of low to high myopia.
Kaluzny et al ${ }^{20}$, evaluated the refractive and visual outcomes of single-step t-PRK in the treatment of mixed astigmatism $(-2.25$ to $-6.0 \mathrm{D})$ with the use of ablation zone $(\geq 7.2 \mathrm{~mm})$. Postoperative uncorrected was $20 / 20$ or better in $60 \%$ of eyes. No eye had lost 2 or more Snellen lines of BCDVA, whereas $6 \%$ of eyes gained 2 or more lines. In $8 \%$ of eyes, haze of low intensity was observed at the periphery, with scores between 0.5 and 1.0, and only one eye getting a score of 2.0. They concluded that mixed astigmatism correction with large ablation zone t-PRK provided good efficacy, safety, predictability and visual outcomes in a 3 -year follow-up.

Visual recovery was significantly faster in the t-PRK group. Complete epithelial wound closure was achieved significantly faster in the t-PRK group. and maximum pain level within the first 4 days after surgery was significantly lower in patients treated with t-PRK. ${ }^{21}$

T-PRK appears to be safe and effective in patients who have mild myopia, with or without astigmatism. The spherical equivalent six months after t-PRK was 0.0 (0.25 to 0.5 ). All patients had a postoperative UCDVA of $20 / 20$ or better in the last follow-up. Transient postoperative corneal haze was observed in five eyes $(6 \%){ }^{22}$

\section{Conclusion}

Our study has confirmed that stream light t-PRK with MMC is effective, safe and predictable method in the treatment of moderate to high myopic astigmatism.

Financial support: No financial support was received for this submission.

\section{Conflicts of interest}

None of the authors has conflict of interest with this submission. 


\section{References}

1. Ang EK, Couper T, Dirani M, Vajpayee RB, Baird PN. Outcomes of laser refractive surgery for myopia. J Cataract Refract Surg. 2009;35(5): 921e933.

2. Kempen JH, Mitchell P, Lee KE, et al. The prevalence of refractive errors among adults in the United States, Western Europe, and Australia. Arch Ophthalmol. 2004;122(4):495e505.

3. Resnikoff S, Pascolini D, Etya'Ale D, et al. Global data on visual impairment in the year 2002. Bull World Health Organ. 2004;82(11): 844e851.

4. Weiss RA, Liaw LH, Berns M, Amoils SP. Scanning electron microscopy comparison of corneal epithelial removal techniques before photorefrac- tive keratectomy. J Cataract Refract Surg. 1999;25(8):1093e1096.

5. Fattah MA, Antonios R, Mosquera SA, Abiad B, Awwad ST. Epithelial erosions and refractive results after single-step transepithelial photore- fractive keratectomy and alcohol-assisted photorefractive keratectomy in myopic eyes: a comparative evaluation over 12 months. Cornea. 2018; 37(1):45e 52 .

6. Abad JC, Talamo JH, Vidaurri-Leal J, Cantu-Charles C, Helena MC. Dilute ethanol versus mechanical debridement before photorefractive keratectomy. J Cataract Refract Surg. 1996;22(10):1427e1433.

7. Pallikaris IG, Karoutis AD, Lydataki SE, Siganos DS. Rotating brush for fast removal of corneal epithelium. J Refract Surg. 1994;10(4): 439e442.

8. Kitazawa Y, Maekawa E, Sasaki S, Tokoro T, Mochizuki M, Ito S. Cooling effect on excimer laser photorefractive keratectomy. J Cataract Refract Surg. 1999;25(10):1349e1355.

9. Lee YG, Chen WY, Petroll WM, Cavanagh HD, Jester JV. Corneal haze after photorefractive keratectomy using different epithelial removal techniques: mechanical debridement versus laser scrape. Ophthalmology. 2001;108(1):112e120.

10. Lee HK, Kim JK, Kim SS, et al. Effect of amniotic membrane after laser- assisted subepithelial keratectomy on epithelial healing: clinical and refractive outcomes. J Cataract Refract Surg. 2004;30(2):334e340.

11. Oh JY, Yu JM, Ko JH. Analysis of ethanol effects on corneal epithelium. Invest Ophthalmol Vis Sci. 2013;54(6):3852e3856.

12. Fadlallah A, Fahed D, Khalil K, et al. Transepithelial photorefractive keratectomy: clinical results. J Cataract Refract Surg. 2011;37:1852-7.
13. Antonios R, Abdul Fattah M, Arba Mosquera S, et al. Single-step transepithelia versus alcohol-assisted photorefractive keratectomy in the treatment of high myopia: a comparative evaluation over 12 months. $\mathrm{Br} \mathrm{J}$ Ophthalmol. 2017;101:1106-12.

14. Wang DM, Du Y, Chen GS, et al. Transepithelial photorefractive keratectomy mode using SCHWIND-ESIRIS excimer laser: initial clinical results. Int $\mathrm{J}$ Ophthalmol. 2012;5:334-7.

15. Luger MH, Ewering T, Arba-Mosquera S. Consecutive myopia correction with transepithelial versus alcohol assisted photorefractive keratectomy in contralateral eyes: one-year results. J Cataract Refract Surg. 2012;38:1414-23.

16. Naderi M, Jadidi K, Mosavi SA, et al. Transepithelial photorefractive keratectomy for low to moderate myopia in comparison with conventional photorefractive keratectomy. J Ophthalmic Vis Res. 2016;11:358-62.

17. Baz O, Kara N, Bozkurt E, Ozgurhan EB, Agca A, Yuksel K, Ozpinar Y, Demirok A. Photorefractive keratectomy in the correction of astigmatism using Schwind Amaris 750s laser. Int J Ophthalmol. 2013 Jun 18;6(3):356-61.

18. Jun I, Kang DSY, Arba-Mosquera S, Choi JY, Lee HK, Kim EK, Seo KY, Kim TI Comparison between Wavefront-optimized and corneal Wavefront-guided Transepithelial photorefractive keratectomy in moderate to high astigmatism. BMC Ophthalmol. 2018 Jun 26;18(1):154. doi: 10.1186/s12886-018-0827-x. PMID: 29940974; PMCID: PMC6020237.

19. Gadde AK, Srirampur A, Katta KR, Mansoori T, Armah SM. Comparison of single-step transepithelial photorefractive keratectomy and conventional photorefractive keratectomy in low to high myopic eyes. Indian J Ophthalmol. 2020 May;68(5):755-761. doi: 10.4103/ijo.IJO_1126_19. PMID: 32317441; PMCID: PMC7350485.

20. Kaluzny BJ, Verma S, Piotrowiak-Słupska I, Kaszuba-Modrzejewska M, Rzeszewska-Zamiara J, Stachura J, Arba-Mosquera S. Three-year outcomes of mixed astigmatism correction with single-step transepithelial photorefractive keratectomy with a large ablation zone. J Cataract Refract Surg. 2021 Apr $1 ; 47(4): 450-458$

21. Gaeckle HC. Early clinical outcomes and comparison between trans-PRK and PRK, regarding refractive outcome, wound healing, pain intensity and visual recovery time in a real-world setup. BMC Ophthalmol. 2021 Apr 16;21(1):181

22. Alasmari M, M Alfawaz A. Transepithelial photorefractive keratectomy to treat mild myopia. Int Ophthalmol. 2021 Mar 24. doi: 10.1007/s10792-021-01816-y. Epub ahead of print. PMID: 33761045. 